\title{
The Organizational Citizenship Behavior Impact on the Adaptive Performance of Moroccan Employees
}

\author{
Zakaria Nejjari $^{*}$, Hanane Aamoum² \\ ${ }^{1 *}, 2$ Laboratory of Scientific Engineering of Organizations, National School of Commerce and Management, \\ Hassan 2 University Casablanca, Morocco
}

\section{Keywords: \\ Organizational Citizenship \\ Behavior, Adaptive \\ Performance, Mutual Help, \\ Team Spirit, Civic Virtues}

\section{Received}

04 October 2020

Received in revised form

14 October 2020

Accepted

17 October 2020

*Correspondence:

za.nejjari@gmail.com

\begin{abstract}
In this article, the relation between organizational citizenship behavior and adaptive performance has been studied. The study was carried out with 67 Moroccan companies. The sample used for this study is composed of 289 employees. This study is fundamentally a quantitative study using the methodology of survey research and SMART PLS by means of structural equation modeling (SEM) to evaluate information. Educational and managerial providers can use the findings to know what the capacity of individuals to adapt to new conditions and requirements of a job as well as the findings help professionals understand individual factors of adaptive performance. The results showed that adaptive performance is influenced by organizational citizenship behaviors-individuals and organizational citizenship behaviors - organizations and that the influence of organizational citizenship behaviors-individuals is greater than that of organizational citizenship behaviorsorganizations. This research provides innovative knowledge regarding the adaptative performance of the employees. Concerning the limitations of the study which also reconfigure lines of future research, it is important to note, in the first place, the geographical restriction of the population under study to the Moroccan employees.
\end{abstract}

In a context of permanent changes in environments and companies, the adaptation of individuals to continuously changing work situations has a crucial dimension (Griffin, Neal, \& Parker, 2007). In such a context, traditional models of employee performance evaluation concern researchers as much as managers because they no longer make it possible to grasp their adaptation to changes in work requirements. A relatively recent concept likely to approach and understand this phenomenon has appeared in the academic sphere. This is how the concept of adaptive performance has 
experienced significant growth in the academic world in recent years (Charbonnier-Voirin \& Roussel, 2012; Griffin et al., 2007). Reflecting a significant evolution in the evaluation of employees' work performance (Griffin et al., 2007), adaptive performance corresponds to their ability to develop new skills, solve new problems, demonstrate interpersonal adaptability, adapting to unpredictable situations and managing the stress that may result (Charbonnier-Voirin \& Roussel, 2012).

A large body of research has focused on identifying the factors that predict adaptive performance. The focus was mainly on the individual (Charbonnier-Voirin, 2013) and managerial levels (Charbonnier-Voirin \& El Akremi, 2011). However, the majority of the variables studied as a history of adaptive performance are frequently used as predictors of other forms of performance. Indeed, although empirical research has distinguished, conceptually and empirically, adaptive performance from other dimensions of performance such as task performance, contextual performance and work performance (Griffin et al., 2007; Shoss, Witt, \& Vera, 2012), the history remains the same, and there appears to be little research on the single predictors of adaptive performance (Jundt, Shoss, \& Huang, 2015). As a result, the literature on adaptive performance could be improved by drawing on other related literature, in particular the literature on organizational citizenship behavior (CCO).

In this paper, we postulate that organizational citizenship behaviors are particularly interesting and promising in explaining adaptive performance. Indeed, the literature suggests a link between adaptive performance and organizational citizenship behaviors. For example, Motowildo, Borman, \& Schmit (1997) implicitly assume that citizen behavior, approached in terms of contextual performance, results in adaptive performance. The authors thus implicitly associate dimensions of organizational citizenship in the sense of Podsakoff and MacKenzie (1994) and that of adaptive performance as defined by Pulakos et al. (2000). Other studies consider that individuals manage changes in their environment through their civic behavior (Podsakoff \& MacKenzie, 1994) and suggest that organizational citizenship behaviors are likely to have an impact on the adaptability of individuals. However, no research to our knowledge has explicitly addressed this problem.

In the first part of the paper, we expose the theoretical constructs and formulate the research hypotheses. In a second, we present the methodological approach, namely a quantitative study conducted on a sample of 289 Moroccans employed by companies in the technology, insurance and banking sector engaged for several years in major reforms. The research results and discussions are detailed and analyzed in a third part. In a final part, we discuss the theoretical contributions and the managerial implications of research.

\section{Organizational Citizenship Behavior and Adaptive Performance: Theoretical Framework}

We define and expose in the following, the theoretical contents of the two concepts. A widespread concept in work and organizational psychology, organizational citizenship has been the subject of numerous studies making it possible to establish its importance in the study of employee behavior towards organizations, its interest in different areas of management, its robustness theory and its universality (Lepine, Erez, \& Johnson, 2002; Podsakoff et al., 2013).

Organizational citizenship behaviors are selfless behaviors that improve the effectiveness of the organization and of individuals. It takes shape through three main behaviors: mutual help, team spirit and civic virtue (Organ, 1988; Organ, Podsakoff, \& MacKenzie, 2006). Mutual help consists in providing colleagues with assistance, reactively or proactively, in order to help them in the exercise of their profession to solve a problem or to avoid them facing difficulties. Team spirit 
refers to an employee's tolerance for work-related difficulties and assesses their ability to accept certain work-related abuses without complaining. Finally, civic virtues are characterized by an employee by showing sustained interest in their organization, by actively participating in all the events (trade fairs, seminars) with which they are associated and by strongly contributing to their development (initiatives, opinions on strategy, role in monitoring threats and opportunities).

Adaptive performance corresponds to a component of employees work performance. It concerns the ability of individuals to modify their behavior to meet the demands linked to changes in the professional environment, a new event, or a change in the situation (Pulakos et al., 2000). Adaptive performance is thus distinguished from performance in the task, which concerns the technical dimension of work (the activities of producing goods and/or services as well as the missions allowing the daily functioning of the organization), and performance. Contextual refers to the behavioral dimension of work (such as cooperation with colleagues, respect for rules and procedures, support for organizational objectives, interpersonal facilitation, dedication to work). Adaptive performance is made up of five main dimensions: solving new problems, developing new skills, managing unpredictable situations and emergencies, stress management and interpersonal adaptability (Charbonnier-Voirin \& Roussel, 2012; Organ, 1988). It emerges from this work that there is an opportunity to explore the influence of variables of organizational citizenship on adaptive performance.

\section{The Impact of Organizational Citizenship Behavior on Adaptive Performance: Previous Empirical Studies}

In what follows, we formulate a series of hypotheses to explore the relationships between the different dimensions of organizational citizenship behavior and adaptive performance.

\section{Mutual Help and Adaptive Performance}

Mutual help consists of providing colleagues with assistance so that they can solve a problem or avoid it, accomplish a task. It often includes dimensions such as altruism, courtesy and conciliation (Podsakoff et al., 2013). This behavior of support for colleagues is benevolent; it is free and it can prove useful and beneficial to the organization in certain difficult professional situations, as are the more or less radical changes affecting the employees and their work. Benevolence indeed allows the individuals who make up the organization to face new circumstances, such as new problems, unpredictable situations, new colleagues, new working methods. Mutual help behaviors concern employees who help a colleague who has difficulties at work, or those who intervene to reduce disagreements or conflicts between colleagues by enabling them to deal more effectively with these conflicts. Such behavior should create stronger (cohesive) relationships between group members (Podsakoff et al., 2013) and help manage stress better by reducing conflict (Podsakoff and MacKenzie, 1994).

The above arguments suggest that employees with higher levels of mutual help should demonstrate more adaptability than those with lower levels of mutual help. These arguments are consistent with previous studies showing that mutual help behaviors are positively correlated to the ability of individuals to contribute to the achievement of their team's objectives (Griffin et al., 2007) and to the sharing of best practices in a logic innovation (Podsakoff \& MacKenzie, 1994). We therefore formulate a first hypothesis:

H1: Mutual help has positive effects on employees' adaptive performance. 


\section{Team Spirit and Adaptive Performance}

Team spirit refers to an individual's tolerance for the difficulties and disadvantages of their work and their ability to endure them without complaining. This dimension also refers, according to the literature (Podsakoff et al., 2013), to the consistency of an attitude, a priori positive, despite the vicissitudes of the life of organizations, sometimes conflicting relationships at work, the need to deal with colleagues' analysis, arguments and decisions. However, situations of change are often accompanied by a stream of significant difficulties (new problems, unpredictable, urgent and potentially stressful situations). They put people to the test, in any case they test their tolerance and their capacity to accept them without complaining, and even to face them with a positive state of mind.

In this sense, previous studies reveal that the perception of team support is a significant antecedent of behaviors contributing to their effectiveness (Griffin et al., 2007). This could translate into benefits, for example in terms of sharing knowledge and skills. Likewise, according to Podsakoff and MacKenzie (1994), employees who display a team spirit demonstrate their willingness to take on new responsibilities or acquire new skills. Team spirit is therefore likely to increase the contribution of employees to adapt, reduce stress in the workplace, solve problems, better manage emergency and develop their skills. We can therefore pose a second hypothesis:

H2: Team spirit has positive effects on employees' adaptive performance.

\section{Civic Virtues and Adaptive Performance}

Civic virtues designate the active participation of individuals in all the manifestations of their organization (such as seminars, fairs), their protection (by defending them around themselves, in their professional and personal life) and the contribution to their development (for example by making suggestions on governance, strategy, organization, by communicating information on possible threats or opportunities). They constitute behavioral benchmarks of employees' commitment to the success of the organization (Podsakoff et al., 2013), indicating that they are actively interested in the life of their organization, or that they would be motivated demonstrate flexibility in a changing situation (Schwartz \& Bilsky, 1990). This dimension therefore reveals the desire to support its organization at all costs with enthusiasm and consistency (Podsakoff et al., 2013). However, in a situation of change, the organization is often in imbalance, more vulnerable. It will activate more than in other circumstances the civic virtues of individuals, who are likely to engender adaptive behaviors.

Similarly, we expect employees who engage in civic virtues by suggesting ideas to improve their work environment are likely to exhibit superior adaptive performance. Finally, Podsakoff and MacKenzie (1994) suggest that employees who volunteer to collect information about changes in their business environment are likely to offer suggestions for responding to those changes. We can expect, and this is our third hypothesis, that civic virtues are positively associated with adaptive performance. We deduce a third hypothesis:

H3: Civic virtue has positive effects on employees' adaptive performance.

\section{Control Variables and Adaptive Performance}

To consider, the influence of other phenomena on the adaptive performance of employees, apart from organizational citizenship, we have introduced four control variables. Indeed, previous studies have shown that individual performance is affected by seniority, age of employees, level of 
education and gender (Charbonnier-Voirin, 2013; Day \& Caroll, 2004). We therefore decided to control these variables in our study.

\section{Employee Seniority and Age}

According to Skirbekk (2004), the performance of individuals at work is highest at the beginning of their career, before stabilizing, and often decreasing towards the end of their career. Decreases in performance with age are also likely to be particularly large when problem solving, learning, and speed of reaction are important in the trade. Although studies that link age to adaptive performance are rare, there are suggestions that older workers are less adaptable (DeArmond et al., 2006). From a different perspective, Dorsey, Cortina, and Luchman (2010) thus link the impact of age and seniority as follows: older workers can excel on certain dimensions of adaptive performance because of the richness of the experience they have acquired. Older people tend to maintain a relatively high level of adaptive performance in tasks where experience and verbal skills are more important. Thus, previous research having examined experience as an antecedent to adaptive performance shows that with a higher experience, an individual can possibly accumulate the necessary knowledge and skills that allow him to adapt (Jundt et al., 2015).

\section{Level of Education and Gender}

The level of qualification has a considerable effect on various dimensions of adaptive performance, in particular the ability to solve problems, interpersonal adaptability as well as the development of new skills (Charbonnier-Voirin, 2013). Finally, gender is likely impact adaptive performance (DeArmond et al., 2006). For example, O'Connell, McNeely, and Hall (2008) found that women show higher levels of adaptability than men. They also found that the level of education was positively linked to the employees' self-assessment of adaptability. If organizational citizenship behavior has an impact on the adaptation of individuals within an organization, it is important to assess these effects to have a more complete vision of the potential impact that organizational citizenship behavior can have on the adaptive performance of individuals. The purpose of this research is therefore to explore the impact of organizational citizenship behaviors on adaptive performance.

\section{Method}

\section{The Study Sample}

The study was carried out with 67 Moroccan companies. The sample used for this study is composed of 289 employees. It is made up of $28.3 \%$ women and $71.7 \%$ men. The average age of respondents is 38.87 years and seniority in office is 19.44 years. The questionnaire was presented and validated during a meeting with 11 managers. Some have volunteered to accompany the study. The latter then took responsibility for informing their employees of the investigation under way and for providing us with professional email addresses. Using a non-probability sampling, we selected members for research at random. We selected a simple random sample of 432 employees of 67 Moroccan companies. We assigned a number to every employee in the company's database from 1 to 700, and we used a random number generator to select 432 numbers. An email including a link to the questionnaire was therefore sent from our mailbox to the 432 employees choosing in March 2019. Among the 432 questionnaires targeted, we received 289 complete questionnaires. The response rate was $66.90 \%$. This rate is considered acceptable, since it is higher than the minimum of $20 \%$ recommended by Gaedeke and Tootelian (1976). 


\section{Measuring Variables}

\section{Independent Variables}

The independent variables were measured with the three scales of Podsakoff and MacKensie (1994) corresponding to the three main forms of organizational citizenship behavior defined by Organ (1988). They are measured by a five-point Likert scale ( $1=$ strongly disagree, $5=$ strongly agree). We present them successively.

Mutual Help. Mutual help perception was measured by five items reflecting the altruism, courtesy and reconciliation behaviors adopted by the employee in the course of his work (Podsakoff \& MacKensie, 1994). This scale measures citizenship behaviors geared towards individuals.

Team Spirit. This variable expresses the willingness of employees to tolerate difficult working conditions without complaining (Organ, 1988). This variable was measured through four items. The scale measures organizational-oriented citizenship behaviors. Like Podsakoff and MacKensie (1994), we opted for a reverse formulation of the items on this scale to measure the lack of team spirit on the part of an individual. Furthermore, in order to be able to use this variable, the scores for these items were inverted during data entry, as recommended by Podsakoff and MacKensie (1994).

Civic Virtues. They correspond to the overall interest expressed by an individual vis-à-vis his organization, reflected in behaviors of active participation. It is an organizational oriented citizenship behavior (Knez, Hjärpe, \& Bryngelsson, 2019). Four items are used for this scale.

\section{The Dependent Variable}

The dependent variable corresponds to the adaptive performance of employees and was measured with the scale of Charbonnier-Voirin and Roussel (2012), created on the basis of the work of Pulakos et al. (2000). Adaptive performance is measured through sixteen items. Employees were asked to rate their adaptive performance on a five-point Likert scale $(1=$ strongly disagree, $5=$ strongly agree). Adaptive performance refers to stress management ( 3 items). It also corresponds to interpersonal and cultural adaptability which measures, through three items, the ability of employees to adapt to changing social and cultural contexts. Among these three items, two had low correlation coefficients $(<0.7)$ with the measured variable and were therefore excluded from the analysis. In addition, three other items measure the development of new skills which refers to the efforts made by the employee to learn new tasks, technologies, procedures, etc. We continued the analysis with the two items with satisfactory correlation coefficients. The resolution of new problems assessed through four items which relate to the ability of individuals to face problems new to them and to solve them. Two items were left out of the analysis due to a weak correlation. Finally, the management of unpredictable situations and emergency measures was considered through three items, the ability of individuals to react to a crisis in an appropriate manner, or even to avoid it. Two items were left out of the analysis.

\section{Results}

\section{Evaluation of the Measurement Model}

Since the measures reflect all the individual items and the reliability of the constructs, the convergent and discriminant validity of all the items must be studied to examine the measurement model. The factor loadings, the composite reliability (CR) and the extracted mean variance (AVE) were used to assess the reliability of the items, the reliability of the constructs and the convergent validity respectively as recommended by Hair et al. (2017). The minimum values are fixed at .7, .7 
and .5 for factor loadings, CR and AVE respectively (Hair et al., 2017). Table 1 shows that the factor load values, CR and AVE are all above the suggested thresholds. Consequently, the reliability of item measurement, internal consistency and convergent validity are satisfactory.

Table 1

Reliability and Convergent Validity Test

\begin{tabular}{|c|c|c|c|c|}
\hline Variables & Items & Loading & $\mathrm{CR}$ & AVE \\
\hline \multirow{5}{*}{ Mutual help } & MH1 & .76 & & \\
\hline & MH2 & .85 & & \\
\hline & MH3 & .82 & .91 & .78 \\
\hline & MH4 & .76 & & \\
\hline & MH5 & .79 & & \\
\hline \multirow{5}{*}{ Team spirit } & TS1 & .77 & & \\
\hline & TS2 & .87 & .93 & .80 \\
\hline & TS3 & .90 & & \\
\hline & TS4 & .79 & & \\
\hline & CV 1 & .83 & & \\
\hline \multirow{3}{*}{ Civic virtue } & $\mathrm{CV} 2$ & .90 & .92 & .79 \\
\hline & $\mathrm{CV} 3$ & .89 & & \\
\hline & CV 4 & .79 & & \\
\hline \multirow{10}{*}{ Adaptive performance } & AP1 & .82 & & \\
\hline & AP2 & .71 & & \\
\hline & AP3 & .76 & & \\
\hline & AP4 & .74 & & \\
\hline & AP6 & .84 & .88 & .75 \\
\hline & AP7 & .91 & & \\
\hline & AP8 & .86 & & \\
\hline & AP10 & .90 & & \\
\hline & AP12 & .89 & & \\
\hline & AP16 & .72 & & \\
\hline
\end{tabular}

Finally, the discriminant validity was assessed by Fornell and Larcker (1981), who stipulates that the AVE of each of the latent variable constructs must be greater than the highest squared construct correlation of another latent variable. Table 2 shows that the item correlation matrix and the square roots of the AVE (diagonal and bold). The diagonal values are all larger than the nondiagonal values in the respective rows and columns, which means adequate discriminant validity. Table 2

Discriminant Validity

\begin{tabular}{lllll}
\hline Variables & 1 & 2 & 3 & 4 \\
\hline Mutual help & $\mathbf{. 8 7}$ & & & \\
Team spirit & .73 & $\mathbf{. 8 2}$ & $\mathbf{. 8}$ & $\mathbf{. 8 8}$ \\
Civic virtue & .75 & .77 & .80 & .78 \\
Adaptive performance & .78 & .80 & \\
\hline
\end{tabular}

\section{Hypothesis Test and Evaluation of the Structural Model}

The quality of the model was assessed by examining the coefficient of determination $\left(\mathrm{R}^{2}\right)$ which indicates the weight of the link between the independent and dependent variables. To designate a satisfactory model, this indicator must be greater than or equal to .2 or .3 (Chin \& Marcoulides, 1998). The value $\mathrm{R}^{2}$ is .81 for the model dependent variable, showing a very good quality of the model. A second criterion $\mathrm{Q}^{2}$ could give us an idea of the predictive relevance of the model. $\mathrm{Q}^{2}$ for adaptive performance is greater than zero, $\mathrm{Q}^{2}=.32$. Therefore, this provides evidence that the observed values are well reconstructed and that the model has predictive relevance. 
In addition to evaluating the $\mathrm{R}^{2}$ values of all endogenous variables, changing the $\mathrm{R}^{2}$ value when a specified exogenous variable is omitted from the model can be used to assess whether the omitted variable has a substantial impact on the endogenous variables (Hair et al., 2017). This measurement is called $\mathrm{f}^{2}$. The recommendations for evaluating $\mathrm{f}^{2}$ are the values of $.02, .15$ and .35 respectively representing small, medium and large effects of the exogenous latent variable. Effect size values less than .02 indicate that there is no effect (Hair et al., 2017). The values of $\mathrm{f}^{2}$ show the importance of civic virtues and mutual help for adaptive performance.

We have proposed in hypotheses 1, 2 and 3 that mutual aid, team spirit and civic virtues positively influence the adaptive performance of Moroccan employees. Table 3 presents the results of the analyzes estimating the effects of the dimensions of organizational citizenship behavior on adaptive performance. The estimates of the control variables are included in the model.

As shown in Table 3 , the coefficient $(\beta)$ for the effect of caring is positive and significant $(\beta=$ $.49, p<.001)$. This result validates the first hypothesis that mutual help is positively related to the adaptive performance of Moroccan employees.

Hypothesis 2 predicts that team spirit has a positive influence on the adaptive performance of Moroccan employees. The effect of team spirit is positive and significant $(\beta=.52, p<.001)$, which indicates that team spirit promotes adaptive performance. Hypothesis 2 is validated. In addition, the effect of team spirit is greater than that of mutual help and civic virtues $(\beta=.36, p<.005)$.

The positive and significant effect of civic virtues makes it possible to validate hypothesis 3 according to which civic virtues are positively related to the adaptive performance of Moroccan employees. However, the effect of civic virtues on adaptive performance is weaker than that of mutual help and team spirit.

We can observe in the results of the control variables on the adaptive performance of Moroccan employees (Table 2) that the effect of age is positive and significant $(\beta=.21, p<.05)$. Age allows employees to acquire a level of maturity which is at the origin of their ability to adapt to changes in their environment.

The seniority variable has a negative and significant effect on adaptive performance $(\beta=-.20, p$ $<.05)$. The assertion that seniority implies adaptive performance is verified in our study. This result implies that, in a context of significant changes, employees with long tenure find it difficult to adapt to changes that affect their work. Finally, gender and level of education have no significant influence on adaptive performance.

Table 3

Path Coefficients

\begin{tabular}{|c|c|}
\hline Rela & Decision \\
\hline $\mathrm{MH}$ & Supported \\
\hline TS & Supported \\
\hline $\mathrm{CV}$ & Supported \\
\hline $\mathrm{AG}$ & Supported \\
\hline SE & Supported \\
\hline ED & Rejected \\
\hline GE & Rejected \\
\hline
\end{tabular}

\section{Discussion}

The present study, by highlighting the significant influence of organizational citizenship behaviors on adaptive performance, fills this gap and extends in particular the research of Jundt et al. (2015), who called for the search for a unique history of adaptive performance. In doing so, adaptive 
performance is not explained exclusively by personal (Johnson, 2001; Jundt et al., 2015) and managerial (Griffith et al., 2007; Jundt et al., 2015) factors, but also by factors related to the work environment, particularly organizational citizenship behaviors. It appears clearly in our study that AP is influenced by organizational citizenship behaviors-Individuals and organizational citizenship behaviors-Organizations and that the influence of organizational citizenship behaviors - Individuals is greater than that of organizational citizenship behaviors-Organizations. It is important to note that this result contradicts that found by Podsakoff et al. (2013) for the impact of organizational citizenship behaviors - Organizations and organizational citizenship behaviorsIndividuals on the evaluation of work performance. By highlighting the significant role of mutual help and team spirit, like that, although less important, of civic virtues, on adaptive performance, our study reveals new effects of organizational citizenship behaviors on the effectiveness of individuals and organizations (Podsakoff et al., 2013). In the same line of our research, two studies were conducted by Yaakobi and Weisberg (2020) to shed light on the role of psychological beliefs on pro-social dynamics in predicting adaptive performance. The results revealed that organizational citizenship behavior (Occupational Efficacy, Collective Efficacy) positively predicted employee adaptive performance (Yaakobi \& Weisberg, 2020). Unlike the results found by our study, the investigation conducted by Jung and Han (2016) on 152 employees in various organizations who work with their team members showed that organizational citizenship behavior (affiliated humor behavior) was negatively related to burnout and adaptive performance (Jung \& Han, 2016). Also, our research shows that the behaviors of organizational citizenship-Individuals have a greater predictive power than the behaviors of organizational citizenship-Organizations on adaptive performance. In doing so, these results support research (Organ et al., 2006; Williams \& Anderson, 1991) on the distinction between these two dimensions of organizational citizenship behavior. Indeed, this research confirms the relevance of distinguishing the two forms of organizational citizenship behavior defined in previous work to grasp the specificity of their effects.

In our research we found that age allows employees to acquire a level of maturity which is at the origin of their ability to adapt to changes in their environment. However, a significant and extremely relevant meta-analysis was performed by $\mathrm{Ng}$ and Feldman (2008), who mentioned the connection between age and adaptative performance and organizational citizenship. These authors stated that investigation over the last two decades has received incoherent results on this association. For example, many analyses have discovered a negative relationship between age and adaptive performance typically, which has occasionally involved contextual performance and organizational citizenship. The justification for this unfavorable correlation is that, as employees grow older, their physical and cognitive functioning decreases. Also, this result contradicts that found by Pulakos et al. (2000) according to which age has no effect on adaptive performance and that of other studies showing that age negatively impacts employee adaptability (DeArmond et al., 2006).

\section{Conclusion}

Based on a sample of employees from 67 Moroccan companies, we conducted a quantitative study on the link between three dimensions of organizational citizenship (mutual aid, team spirit and civic virtues) and adaptive performance. The main focus of the study is that adaptive performance is influenced to a great extent by mutual help and team spirit and by civic virtues to a lesser extent. These three dimensions of organizational citizenship behaviors constitute important explanatory factors for adaptive performance. The study also highlights the role played by age and seniority on 
adaptive performance, as well as it reveals the significant weight of organizational citizenship behaviors-Individuals compared to organizational citizenship behaviors-Organization adaptive performance.

This research, by emphasizing the role played by organizational citizenship behaviors, contributes from a theoretical point of view to a better knowledge of the antecedents of adaptive performance as well as to the identification of new positive effects of organizational citizenship behaviors. At the managerial level, it leads to recommending evolution in the guides and methods for selecting and conducting annual evaluation interviews as well as professional interviews to consider the importance of the role played by organizational citizenship behaviors and adaptive performance. In the development of the performance of individuals and in the management of professional trajectories. It also involves implementing various management practices to facilitate organizational citizenship behaviors among employees.

\section{Theoretical and Managerial Contribution}

Jundt et al. (2015) argue that a major limitation of research on adaptive performance is the absence of unique predictors for this measure of performance. However, in the absence of a specific history, it is difficult to take effective actions to act, in a targeted manner, on this form of performance which has become essential in a context characterized by continuous upheavals. It is a question of identifying the specific processes in which individuals must engage to be able to adapt to their context. Our research addresses this question by identifying a history not examined in the literature, organizational citizenship. However, numerous studies implicitly explain adaptive performance by factors linked to organizational citizenship (Padsakoff \& MacKenzie, 1994).

The results of this study thus contribute respectively to the literature devoted to adaptive performance and to that dedicated to organizational citizenship. The outcomes of this research represent a breakthrough in the study of adaptive performance in two respects. First, the major contribution is to consider organizational citizenship behaviors as a history of adaptive performance. This research contributes to the study of individual factors of adaptive performance. It indeed highlights the role of age and seniority in certain dimensions of adaptive performance. By focusing specifically on adaptive performance and emphasizing the role of seniority and age, this result extends and complements studies on individuals' work performance (Day \& Caroll, 2004; Johnson, 2001; Skirbekk, 2004) more specifically to adaptive performance and to the study of the role of individual antecedents (Charbonnier-Voirin, 2013; Jundt et al., 2015). The results of this study constitute in two respects an advance in the specific field of behaviors of organizational citizenship. First, by demonstrating their effects on the adaptive performance of individuals, our study contributes to fueling a field of research little investigated by specialists in the field (Podsakoff et al., 2009, 2013), the majority of studies on behavior organizational citizenship examining its antecedents (Ilies et al., 2007; Lepine et al., 2002; Ohana, 2016). This research reveals several managerial implications making it possible to increase the capacity of individuals to adapt to new conditions and requirements of a job. Our study shows that organizational citizenship behaviors play an important role in the development of employees' adaptive performance. We first draw the attention of managers to the crucial importance of selecting people with the attributes of organizational citizenship behaviors leading to adaptive performance. Consequently, if the company evolves in a changing sector having consequences on the working environments of the individuals, the recruitment processes must from now on consider new criteria, in particular the mutual help, the team spirit and the civic virtues and integrate them into the application evaluation 
documents. Managers can also seek to develop the organizational citizenship behaviors of their employees. In order to stimulate mutual help, team spirit and civic virtues, devices favoring the collective should be favored (such as the organization of working groups on strategic projects, the development of systems of collective valorization such as variable team and company compensation, the development of shared values, the organization of regular friendly events to preserve the unity of the company). We then recommend to regularly monitor the level of organizational citizenship behavior of company or team collaborators and to use them as a predictive indicator of adaptive performance. This assessment could thus be included in the guide to annual progress interviews and would consist in systematically rating mutual help, team spirit and civic virtues. It would therefore be a question of adding three new items to those that are often found under the label of relational qualities, involvement, dynamism. The evaluation of these three items could give rise to an aggregated score of organizational citizenship behavior level. A low level of organizational citizenship behavior would therefore suggest difficulties in adapting to new professional situations. In the extension, it would be a question of monitoring the evolution of these three items over time to durably increase the adaptive potential of individuals. Another recommendation would be to suggest to managers to adopt a set of good practices, awareness and support, promoting organizational citizenship behaviors, and therefore adaptive performance. These include, for example 1) establishing different management practices to facilitate organizational citizenship behaviors among employees such as knowledge transfer, information exchange, and fostering mutual help, 2) highlight with fair and formal rewards the efforts of team members who demonstrate organizational citizenship behavior, and 3) Highlight team results instead of business results for the employee can see the impact that their behaviors can have.

\section{Limits and Future Research}

If this research constitutes a step towards the identification of factors specific to adaptive performance, in this case the behaviors of organizational citizenship and the behaviors of organizational citizenship-Individuals, it presents two main limits. The first concerns the sample selected for the study. Indeed, it is limited to employees working in Moroccan companies. The second limit concerns the assessment of adaptive performance and organizational citizenship. These are not observed based on employee behavior and therefore have not been observed objectively.

To conclude, we suggest some additional lines of research. Future studies could integrate different types of performance into the same model to isolate the effect of organizational citizenship on adaptive performance. A second line of research consists in replicating a similar study in different contexts. Indeed, taking into account the organizational and sectoral specificities of the company studied, such research would make it possible to assess the reproducible nature of the results obtained and consequently the influence of certain internal (linked to the company) and external (linked industry). The third line of research focuses on how to assess adaptive performance and organizational citizenship. It would be interesting to combine self-assessment with an assessment from other stakeholders (such as colleagues and managers). 


\section{References}

Charbonnier-Voirin, A. (2013). L'influence des traits de personnalité sur la performance adaptative des salariés [The influence of personality traits on the adaptive performance of employees]. Revue de Gestion des Ressources Humaines, 88(2), 17-32.

Charbonnier-Voirin, A., \& El Akremi, A. (2011). L'effet de l'habilitation sur la performance adaptative des employés [The effect of empowerment on adaptive employee performance]. Relations Industrielles / Industrial Relations, 66(1), 122-149.

Charbonnier-Voirin, A., \& Roussel, P. (2012). Adaptive performance : A new scale to measure individual performance in organizations. Canadian Journal of Administrative Sciences / Revue Canadienne des Sciences de l'Administration, 29(2), 280293.

Chin, W., \& Marcoulides, G. (1998). The partial least squares approach to structural equation modeling. Modern Methods for Business Research, 8(2), 295-336.

Day, A., \& Carroll, S. (2004). Using an ability-based measure of emotional intelligence to predict individual performance, group performance, and group citizenship behaviors. Personality and Individual Differences, 36(1), 1443-1458.

DeArmond, S., Tye, M., Chen, P. Y., Krauss, A., Rogers, D. A., \& Sintek, E. (2006). Age and gender stereotypes: New challenges in a changing workplace and workforce. Journal of Applied Social Psychology, 36(9), 2184-2214

Dorsey, D. W., Cortina, J. M., \& Luchman, J. (2010). Adaptive and citizenship-related behaviors at work. In J. L. Farr \& N. T. Tippins (Eds.), Handbook of employee selection (p. 463-487). Routledge/Taylor \& Francis Group.

Fornell, C., \& Larcker, D. F. (1981). Evaluating structural equation models with unobservable variables and measurement error. Journal of Marketing Research, 18(1), 39-50.

Gaedeke, R. M., \& Tootelian, D. H. (1976). The Fortune "500" list: An endangered species for academic research. Journal of Business Research, 4, 283-288.

Griffin, M., Neal, A., \& Parker, S. (2007). A new model of work role performance: Positive behavior in uncertain and interdependent contexts. Academy of Management Journal, 50(2), 327-347.

Hair, J. F., Hollingsworth, C. L., Randolph, A. B., \& Chong, A. Y. L. (2017). An updated and expanded assessment of PLS-SEM in information systems research. Industrial Management and Data Systems, 117(3), 442-458.

Ilies, R., Nahrgang, J., Morgeson, F. (2007). Leader-member exchange and citizenship behaviors: A meta-analysis. The Journal of Applied Psychology, 92(1), 269-277.

Johnson, J. (2001). The relative importance of task and contextual performance dimensions to supervisor judgments of overall performance. The Journal of Applied Psychology, 86(5), 984-996.

Jundt, D. K., Shoss, M. K., \& Huang J. L. (2015). Individual adaptive performance in organizations: A review. Journal of Organizational Behavior, 36(1), S53-S71.

Jung, E., \& Han, T. (2016). The effects of humor behavior on adaptive performance and contribution to team members' adaptive performance: The mediating effects of burnout. Korean Journal of Industrial and Organizational Psychology, 29(3), 465-489.

Knez, I., Hjärpe, D., \& Bryngelsson, M. (2019). Predicting organizational citizenship behavior: The role of work-related self. SAGE Open.

Lepine, J. A., Erez A., \& Johnson, D. E. (2002). The nature and dimensionality of organizational citizenship behavior: A critical review and meta-analysis. Journal of Applied Psychology, 87(1), 52-65

Motowildo, S., Borman, W., \& Schmit, M. (1997). A theory of individual differences in task and contextual performance. Human Performance, 10(2), 71-83.

Ng, T. W. H., \& Feldman, D. C. (2008). The relationship of age to ten dimensions of job performance. Journal of Applied Psychology, 93(2), 392-423.

O'Connell, D. J., McNeely, E., \& Hall, D. T. (2008). Unpacking personal adaptability at work. Journal of Leadership and Organizational Studies, 14(3), 248-259.

Ohana, M. (2016). Voice, affective commitment and citizenship behavior in teams: The moderating role of neuroticism and intrinsic motivation. British Journal of Management, 27(1), 97-115.

Organ, D.W. (1988). Organizational citizenship behavior: The good soldier syndrome. Lexington Books/DC Heath and Com.

Organ, D. W., Podsakoff, P. M., \& MacKenzie, S. B. (2006). Foundations for organizational science: Organizational citizenship behavior: Its nature, antecedents, and consequences Thousand Oaks, CA: SAGE Publications, Inc.

Podsakoff, P. M., \& MacKenzie, S. B. (1994). Organizational citizenship: Behaviors and sales unit effectiveness. Journal of Marketing Research, 31(3), 351-363.

Podsakoff, P., MacKenzie, S., Paine, J., \& Bachrach, D. (2013). Organizational citizenship behaviors: A critical review of the theoretical and empirical literature and suggestions for future research. Journal of Management, 26(3), 513-563.

Pulakos, E. D., Arad, S., Donovan, M. A., \& Plamondon, K. E. (2000). Adaptability in the workplace: Development of a taxonomy of adaptive performance. Journal of Applied Psychology, 85(4), 612-624. 
Schwartz, S., \& Bilsky, W. (1990). Toward a theory of the universal content and structure of values: Extensions and cross-cultural replications. Journal of Personality and Social Psychology, 58(5), 878-891.

Shoss, M. K., Witt, L. A., \& Vera, D. (2012). When does adaptive performance lead to higher task performance? Journal of Organizational Behavior, 33(7), 910-924.

Skirbekk, V. (2004). Age and individual productivity: A literature survey. Vienna Yearbook of Population Research, 2(1), 133153.

Williams, L. J., \& Anderson, S. E. (1991). Job satisfaction and organizational commitment as predictors of organizational citizenship and in-role behaviors. Journal of Management, 17(3), 601-617.

Yaakobi E., \& Weisberg, J. (2020). Organizational citizenship behavior predicts quality, creativity, and efficiency performance: The roles of occupational and collective efficacies. Frontiers in Psychology, 11, 758.

Yen, H. R., \& Niehoff, B. P. (2004). Organizational citizenship behaviors and organizational effectiveness: Examining relationships in Taiwanese banks. Journal of Applied Social Psychology, 34(8), 1617-1637. 